\title{
Long-Term Depression Is Not Induced by Low-Frequency Stimulation in Rat Visual Cortex In Vivo: A Possible Preventing Role of Endogenous Brain-Derived Neurotrophic Factor
}

\author{
Bin Jiang, ${ }^{1,2}$ Yukio Akaneya, ${ }^{1,2}$ Yoshio Hata, ${ }^{1,2}$ and Tadaharu Tsumoto ${ }^{1,2}$ \\ ${ }^{1}$ Core Research for Evolutional Science and Technology, Japan Science and Technology Corporation, Kawaguchi, Saitama 332-0012 Japan, and ${ }^{2}$ Division of \\ Neurophysiology, Osaka University Graduate School of Medicine, 2-2 Yamadaoka, Suita 565-0871, Japan
}

Low-frequency stimulation (LFS) at $1 \mathrm{~Hz}$ for $15 \mathrm{~min}$ is an effective protocol to induce homosynaptic long-term depression (LTD) in visual cortical slices. It is reported that LFS becomes ineffective when brain-derived neurotrophic factor (BDNF) is applied to slices. It is not known, however, whether such a protocol induces LTD in visual cortex in vivo, and whether endogenous BDNF has the same or similar action. To address these questions, we recorded field potentials of rat visual cortex evoked by stimulation of lateral geniculate nucleus, white matter, or cortical layer IV. We found that LFS did not induce LTD of cortical responses in vivo. To test the possibility that spontaneous activity from retinas would interfere with the induction of LTD, both eyes were removed or inactivated by tetrodotoxin. LTD was not induced in these conditions either. To test whether the difference in temperature between the two preparations is a factor for the discrepancy, the temperature of slices was increased from 31 to $37^{\circ} \mathrm{C}$. LTD was induced in slices at either temperature. Then, we hypothesized that endogenous BNDF and its receptors, TrkB, prevent the induction of LTD. To test this, we infused the cortex with an inhibitor of Trk receptor tyrosine kinases, anti-TrkB IgG1, anti-BDNF, and anti-neurotrophin 4/5 antibodies. LTD was induced when the BDNFTrkB system was blocked. In slices, the level of phosphorylation of Trks was found to decrease with time. These results indicate that activation of TrkB signal pathway prevents LFS from inducing synaptic depression in visual cortex in vivo.

Key words: long-term depression; LTD; low-frequency stimulation; brain-derived neurotrophic factor; BDNF; visual cortex; in vivo; slices

\section{Introduction}

Long-term depression (LTD) of synaptic transmission, a counterpart of long-term potentiation, can be induced in the visual cortex of kittens and young rats and is supposed to provide a basis for experience-dependent modifiability of visual cortical neurons during the critical period of postnatal development (Tsumoto and Suda, 1979; Bear et al., 1987; Tsumoto, 1992; Kirkwood et al., 1993; Linden and Connor, 1995; Singer, 1995; Dudek and Friedlander, 1996) (for review, see Katz and Shatz, 1996). Among the three forms of LTD, i.e., homosynaptic, heterosynaptic, and associative LTD, the first form of LTD is induced reliably in visual cortex by prolonged stimulation of afferents at low-frequency, such as $1 \mathrm{~Hz}$ for $15 \mathrm{~min}$ [low-frequency stimulation (LFS)] (Kirkwood et al., 1993; Haruta et al., 1994; Kirkwood and Bear, 1994; Dudek and Friedlander, 1996; Sermasi et al., 1999; Perrett et al., 2001). Because all of these results were obtained in slice preparations of visual cortex, however, an important question of whether homosynaptic LTD is induced by LFS in the cortex in vivo has not been answered yet.

\footnotetext{
Received Dec. 3, 2002; revised Feb. 11, 2003; accepted Feb. 18, 2003.

This work was supported in part by a Grant-in-Aid for Scientific Research on Priority Areas (C)-Advanced Brain Science Project from the Ministry of Education, Culture, Sports, Science and Technology of Japan.

Correspondence should be addressed to Dr. Tadaharu Tsumoto, Division of Neurophysiology, Osaka University Graduate School of Medicine (D-14), 2-2 Yamadaoka, Suita 565-0871, Japan. E-mail: ttsumoto@nphys.med.osakau.ac.jp.

Copyright $\odot 2003$ Society for Neuroscience $\quad$ 0270-6474/03/233761-10\$15.00/0
}

An application of exogenous brain-derived neurotrophic factor (BDNF) has been reported to block the induction of LTD of excitatory synaptic transmission in slice and neuron culture preparations of rat visual cortex (Akaneya et al., 1996; Huber et al., 1998; Kinoshita et al., 1999; Kumura et al., 2000) or to attenuate LTD in slice preparations of rat hippocampus (Ikegaya et al., 2002), although functional blockade of BDNF receptors was reported not to affect visual cortical LTD (Sermasi et al., 2000). $\mathrm{BDNF}$ is an endogenous protein, which is abundantly present in visual cortex (Rossi et al., 1999; Pollock et al., 2001; Tropea et al., 2001; Ichisaka et al., 2003). Thus, there is another question of whether blockade of function of endogenous BDNF and its receptors facilitates the induction of homosynaptic LTD in the visual cortex in vivo or not.

To address these questions, we recorded field potentials from layer II/III of visual cortex of anesthetized rats in vivo and applied LFS to three sites along the afferent pathway to the cortex. We found that LTD cannot be induced by LFS applied to any of the sites in the in vivo brain. We also found that homosynaptic LTD was induced by LFS when activities of endogenous BDNF or its receptors were blocked by a drug or antibodies. These results suggest that the LFS-induced form of homosynaptic LTD may not operate in the in vivo cortex, and endogenous BDNF is a candidate molecule to prevent LFS from inducing synaptic depression in the intact visual cortex. The present results further indicate that LFS and slice preparations should be used with caution in the study of cortical LTD. 
Parts of this paper have been published previously in abstract form (Jiang et al., 2002).

\section{Materials and Methods}

Animals and anesthesia. Sprague Dawley rats, ranging in age from postnatal days 17 to 23 (P17-P23), were used. The animals were raised with water and food available ad libitum and kept on $12 \mathrm{hr}$ light/dark cycle. The experimental procedures met with the regulations of the Animal Care Committee of Osaka University Graduate School of Medicine. The rats were anesthetized with an intraperitoneal injection of pentobarbital sodium (Nembutal; Abbott laboratories, North Chicago, IL) at 20-30 $\mathrm{mg} / \mathrm{kg}$ and then placed in a stereotaxic frame. The anesthesia was maintained throughout experiments by injecting a supplemental dose of Nembutal $(0.5-1 \mathrm{mg} / \mathrm{hr})$ if necessary to keep the level of anesthesia. Rectal temperature was kept at $37 \pm 0.5^{\circ} \mathrm{C}$ with a servo-heating pad. An appropriate dose of atropine sulfate $(0.5 \mathrm{mg} / \mathrm{kg})$ was injected subcutaneously to reduce respiratory secretions, and heart rate was monitored continuously to ensure preparation stability.

In part of the experiments, both eyes of anesthetized rats were removed after the stimulating electrodes had been placed in the sites that will be described later. For this, both eyelids were cut to make muscles and vessels surrounding the eyeballs visible. After ligating the major vessels, the muscles and nerves were cut so that the eyes were removed. The orbital cavities were stuffed with absorbent cotton, and the eyelids were sutured. In another series of experiments, tetrodotoxin (TTX) was injected into both eyes to block retinal activity in the same way as described previously (Desai et al., 2002). The injection solution contained $3 \mathrm{~mm}$ TTX (Sigma, St. Louis, MO) dissolved in $25 \mathrm{~mm}$ citrate buffer. A 33 gauge cannula connected to a Hamilton syringe through a polyethylene tube was inserted into the vitreous cavity at the ora serrata. Infusion was performed by a microinfusion pump with the rate of $0.5 \mu \mathrm{l} / \mathrm{min}$. The total volume injected to one eye was $0.8-1 \mu \mathrm{l}$.

Electrophysiology. A bipolar stimulating electrode with a tip separation of $\sim 0.3 \mathrm{~mm}$ was inserted into the dorsal lateral geniculate nucleus (LGN). Stereotaxic coordinates for this were as follows: $3.8-4.0 \mathrm{~mm}$ posterior to the bregma, 3.5-4.0 mm lateral to the midline. The depth of tips was adjusted to record maximal field responses to flashes of light given to the eye contralateral to the LGN. In another group of rats, a bipolar stimulating electrode of the same type as above was inserted into the cerebral cortex $3.5-4.0 \mathrm{~mm}$ lateral to the midline, $7.0 \mathrm{~mm}$ posterior to the bregma at the depth of $1.6-1.8 \mathrm{~mm}$ to stimulate white matter or $4.2-4.5 \mathrm{~mm}$ lateral to the midline, $6.8 \mathrm{~mm}$ posterior to the bregma at the depth of $0.6-0.8 \mathrm{~mm}$ to stimulate layer IV of the visual cortex. In some cases, the position of the stimulating electrodes was verified with histology, as will be mentioned later. For monopolar recording of cortical field potentials, a glass micropipette (single-barrel borosilicate glass micropipettes, $0.86 \mathrm{~mm}$ inner diameter), pulled with a horizontal puller (model P-97, Sutter Instruments, Novato, CA), was placed in layer II/III of the cortex by lowering it vertically $500 \mu \mathrm{m}$ below the pial surface. To remove the surface dimple, the electrodes were retracted by $\sim 50 \mu \mathrm{m}$. To avoid the cortical area near the insertion point of stimulating electrodes, the insertion site of recording electrodes was adjusted so that it was $7.0 \mathrm{~mm}$ posterior to the bregma and 3.0-4.0, 4.2-4.5, and $3.5 \mathrm{~mm}$ lateral to the midline in case of LGN, white matter, and layer IV stimulation, respectively. The indifferent electrode was connected to a ground screw fixed with the bone overlying the cerebellum. The recording electrodes were filled with $3 \mathrm{M} \mathrm{NaCl}$. The resistance was $0.5-1 \mathrm{M} \Omega$. In part of the experiments, glass micropipettes were filled with $0.5 \mathrm{M}$ sodium acetate containing $2 \%$ Pontamine sky blue to mark the tip position of recording electrodes. In these experiments, the current (5-10 $\mu \mathrm{A}$, electrode negative) was passed through the electrode until a blue spot appeared on the cortical surface. Then, the rats were perfused transcardially with PBS, followed by $10 \%$ Formalin. The brain was removed and stored overnight in the same fixative with $10 \%$ sucrose. The block of the brain was sectioned at $50 \mu \mathrm{m}$, mounted, and stained with cresyl violet.

Field potentials were evoked by single shock stimuli of $0.2 \mathrm{msec}$ duration at the intensity of $0.2-0.9 \mathrm{~mA}$ for stimulation of LGN and 15-60 $\mu \mathrm{A}$ for stimulation of white matter and layer IV. Evoked responses were amplified and filtered at $0.1-3 \mathrm{kHz}$, digitized at $20 \mathrm{kHz}$, and stored on a
Macintosh computer (Apple Computers, Cupertino, CA) for offline analysis. Before the beginning of recordings, a full input-output curve was observed, and stimulation at the intensity yielding the amplitude of field potentials at $50-60 \%$ of the maximal was used for subsequent experiments. Test shocks were given at $30 \mathrm{sec}$ intervals for 20-30 min for baseline recordings before the application of LFS. LFS usually consisted of 900 pulses at $1 \mathrm{~Hz}$ for $15 \mathrm{~min}$, except for the case in which 1800 pulses were applied at $1 \mathrm{~Hz}$ for $30 \mathrm{~min}$.

Treatment with antibodies, drug, and vehicle solution. Anti-human BDNF polyclonal antibody (Promega, Madison, WI), anti-human neurotrophin 4/5 (NT4/5) polyclonal antibody (Chemicon, Temecula, CA), and anti-TrkB IgG1 (clone 47; BD Transduction Laboratories, Lexington, $\mathrm{KY}$ ) were prepared at the concentration of $1 \mu \mathrm{g} / \mu \mathrm{l}$ dissolved in Ringer's solution and stored at $4^{\circ} \mathrm{C}$ until used. A broad-spectrum inhibitor for Trk receptor tyrosine kinases, K252a (Biomol, Plymouth Meeting, PA), was prepared at the concentration of 10,20 , and $40 \mu \mathrm{M}$, respectively, with dimethylsulfoxide (DMSO). The final concentration of DMSO was $0.1,0.2$, and $0.4 \%(\mathrm{v} / \mathrm{v})$, respectively. A 33 gauge metal cannula with beveled tip was inserted vertically into the visual cortex for the depth of $1.0 \mathrm{~mm}$ with the bevel facing toward the recording electrode, and the distance between the tips of this cannula and the recording electrode was $\leq 1 \mathrm{~mm}$. After the recording electrode and cannula were positioned as mentioned above, $5 \%$ agar dissolved in saline was applied over the exposed brain to prevent the surface from drying and to reduce movement of the cortex. Solutions were applied to the cortex through polyethylene tubes connected to a Hamilton syringe by a microinfusion pump (Harvard Apparatus, Holliston, MA) with the infusion rate of 0.08 $\mu \mathrm{l} / \mathrm{min}$.

Slice preparation. Slices were prepared as described previously (Akaneya et al., 1997). Sprague Dawley rats at P17-P23 were deeply anesthetized with Nembutal, and their brains were quickly removed and placed in the chilled artificial CSF (ACFS). A section of tissue containing the primary visual cortex was blocked, and coronal slices ( $400 \mu \mathrm{m}$ thick) were cut from this block in the chilled ACSF with a rotor slicer (DTY7000; Dosaka, Kyoto, Japan). Slices were transferred to a submerged type of recording chamber and maintained for $>1 \mathrm{hr}$ before the initiation of recordings. During this period, the temperature of the ACSF perfusing the slices was slowly increased to 31 or $37^{\circ} \mathrm{C}$. The rate of perfusion was $200 \mathrm{ml} / \mathrm{hr}$. The composition of medium was as follows (in $\mathrm{mm}$ ): $124 \mathrm{NaCl}, 5 \mathrm{KCl}, 1.2 \mathrm{KH}_{2} \mathrm{PO}_{4}, 1.3 \mathrm{MgSO}_{4}, 2.4 \mathrm{CaCl}_{2}$, and 10 glucose. The medium was aerated with $95 \% \mathrm{O}_{2}-5 \% \mathrm{CO}_{2}$. To record field potentials, a glass micropipette filled with $0.5 \mathrm{M}$ sodium acetate containing $2 \%$ Pontamine sky blue $(<4 \mathrm{M} \Omega)$ was inserted into layer II/III of the cortex, and a bipolar stimulating electrode was placed in the middle of cortical thickness. Field potentials were evoked by stimuli of $0.2 \mathrm{msec}$ duration at the intensity of 15-300 $\mu \mathrm{A}$. Evoked responses were amplified and filtered at $0.1-3 \mathrm{kHz}$, digitized at $20 \mathrm{kHz}$, and stored on a Macintosh computer for offline analysis. Stimulation at the intensity yielding the amplitude of field potentials at $50-60 \%$ of the maximal was used for subsequent experiments. Test shocks were given to layer IV at $30 \mathrm{sec}$ interval for $10 \mathrm{~min}$ for baseline recordings before the application of LFS. LFS usually consisted of 900 pulses at $1 \mathrm{~Hz}$ for $15 \mathrm{~min}$.

Data analysis. The acquisition and analysis of field potentials were performed using a Maclab software (ADInstruments, Dunedin, New Zealand). To quantitatively evaluate effects of LFS, four consecutive responses were averaged, and the amplitude of field potentials was measured, as will be described in Results. Changes in the amplitude were assessed with values obtained $1 \mathrm{hr}$ after the end of LFS relative to those 20 and $10 \mathrm{~min}$ before the LFS in the in vivo and in vitro preparations, respectively. Statistical analysis was performed with the Student's $t$ test unless otherwise mentioned.

Immunohistochemistry with anti-BDNF antibody, anti-NT4/5 antibody, and anti-TrkB IgG1. Visual cortices of the rats were sectioned with a freezing microtome at $50 \mu \mathrm{m}$ thickness and preincubated for $4 \mathrm{hr}$ with PBS containing 5\% skimmed milk and $0.3 \%$ Triton X-100. Then, tissues were incubated with biotinylated goat anti-chicken IgG for BDNF polyclonal antibody, goat anti-mouse IgG for TrkB IgG1, and goat anti-rabbit IgG for NT4/5 polyclonal antibody, respectively, overnight at $4^{\circ} \mathrm{C}$ in $\mathrm{PBS}$ containing $0.3 \%$ Triton X-100 and $2 \%$ horse serum. The immunohisto- 
chemical reaction was developed using the Vectastain $\mathrm{ABC}$ kit (Vector Laboratories, Burlingame, CA) and intensified by incubation with $0.2 \%$ ammonium nickel sulfate.

Western blot analysis of the in vivo cortex with anti-pY490-Trk receptor antibody. The rats were decapitated after K252a ( $20 \mu \mathrm{M})$ was infused into the visual cortex for $1 \mathrm{hr}$ or after anti-TrkB IgG1, anti-BDNF antibody, or anti-NT4/5 antibody was infused into the visual cortex for $2 \mathrm{hr}$ (total dose of $9.6 \mu \mathrm{g}$ ). Then, the brain was removed quickly and rinsed with ice-cold PBS. A cube of tissue from the visual cortex $(2 \times 2 \times 2 \mathrm{~mm})$ containing the injection site was excised, and the cube of tissue from the visual cortex of the other hemisphere was excised as control. The tissue block was hand-homogenized with 15 strokes in $300 \mu \mathrm{l}$ of freshly made lysis buffer consisting of $25 \mathrm{~mm}$ HEPES, $150 \mathrm{~mm} \mathrm{NaCl}, 1 \mathrm{~mm}$ EDTA, and $1 \%$ Triton X-100 in a $2 \mathrm{ml}$ glass syringe. After shaking the homogenate for $30 \mathrm{~min}$ at $4^{\circ} \mathrm{C}$ and centrifuging at $15,600 \times g$, the supernatants were used for Western blot analysis. Supernatants in 10\% glycerol, $2.3 \%$ SDS, $0.01 \%$ bromophenol blue, and $0.5 \% 2$-mercaptoethanol in $62.5 \mathrm{~mm}$ Tris$\mathrm{HCl}, \mathrm{pH} 6.8$, were boiled for $3 \mathrm{~min}$, and one portion of the supernatants was used for protein level determination with the Bio-Rad Protein Assay (Bio-Rad, Hercules, CA). Equal amount of proteins was loaded to SDSPAGE gels. After separation, proteins were transferred overnight to nitrocellulose membrane. Then, blots were blocked in 5\% skimmed milk in T-PBS (50 mm PBS, pH 7.4, and 0.1\% Tween 20) for $30 \mathrm{~min}$ at room temperature and incubated with shaking for $2 \mathrm{hr}$ at room temperature in T-PBS with rabbit polyclonal antibody, which selectively recognizes Tyr490-phosphorylated, active Trk receptor tyrosine kinases (1:1000; Cell Signaling Technology, Beverly, MA). After incubation with the primary antibody, the membrane was washed three times with T-PBS, and the blots were exposed to the donkey anti-rabbit IgG peroxidase-linked antibody (1:5000; Amersham Biosciences, Piscataway, NJ) with shaking for $1 \mathrm{hr}$ and developed using ECL Western blotting detector reagents (Amersham Biosciences). After conversion to Adobe Photoshop (Adobe Systems, San Jose, CA) images through a scanner, signals of the films were analyzed densitometrically using NIH Image software. Then, the membranes were stripped and reprobed with the mouse monoclonal antibody raised against TrkB (1:1000; BD Transduction Laboratories). After washing three times, the blots were exposed to a goat anti-mouse IgG peroxidase-linked antibody (1:4000; Santa Cruz Biotechnology, Santa Cruz, CA).

Western blot analysis of cortical slices. Slices containing visual cortex were prepared from the rat, as described above. Then, the slices were either quickly frozen and stored at $-80^{\circ} \mathrm{C}$ (control) or placed in a bath of oxygenated ACSF, incubated at $31^{\circ} \mathrm{C}$ for 1,2 , or $4 \mathrm{hr}$, and then frozen at $-80^{\circ} \mathrm{C}$. Protein extraction from the visual cortex and Western blotting were performed, as in the in vivo preparations. Briefly, two pieces of slices for each condition were homogenized with 15 strokes in $200 \mu \mathrm{l}$ of freshly made lysis buffer. The proteins were transferred to the membrane, which was then cut into two pieces according to the protein size marker. The upper piece was incubated with anti-p490-Trk antibody, and the lower one was incubated with anti- $\alpha$-tubulin (1:5000; Sigma) whose signals were used for normalization of the protein levels of anti-p490-Trk and TrkB. Then, the upper piece of membrane was stripped and reprobed with anti-TrkB antibody. All of the data were expressed as mean \pm SEM of the control values (100\%) unless otherwise mentioned.

\section{Results \\ Cortical field potentials}

To observe cortical neuronal activity for a long time in vivo, we recorded field potentials of layer II/III evoked by stimulation of LGN, underlying white matter, and layer IV of the cortex. For this, a recording electrode was placed in the cortex $0.2-0.5 \mathrm{~mm}$ from the surface, as reported previously (Jiang et al., 2001). In all of the seven cases in which recorded sites were marked with Pontamine sky blue and verified with histology, the recording sites were confirmed to be located in layer II/III of the primary visual cortex. Also, the tips of stimulating electrodes were confirmed to be located in the intended sites in all of the nine cases in which histological examination was performed after recordings.

\section{A. LGN stimulation}

\section{a. Control}

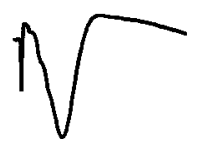

c. Recovery acid

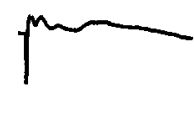

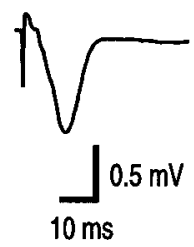

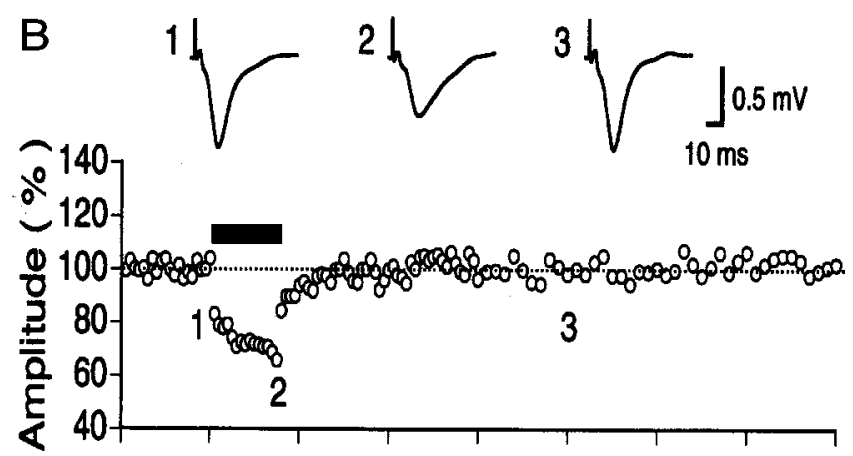

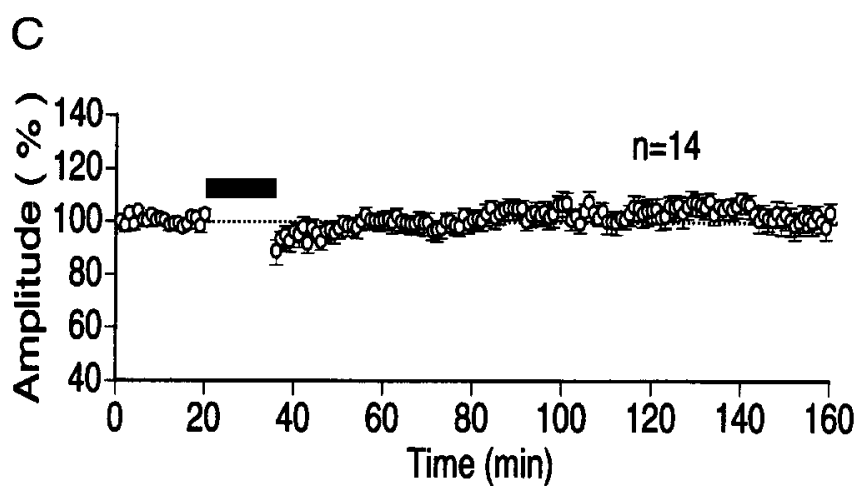

Figure 1. Field potentials elicited by LGN stimulation and ineffectiveness of LFS to induce LTD in visual cortex in vivo. A, Examples of cortical field potentials evoked by stimulation of $L G N$. $a$, Field potentials recorded just before an application of kynurenic acid. In this and the following records, four sweeps were averaged, and the downward deflection corresponds to negativity. $b$, An example of records obtained just before cessation of the application of kynurenic acid (50 $\mathrm{mm}$ ) for $20 \mathrm{~min}$ at a flow rate of $0.08 \mu \mathrm{l} / \mathrm{min}$. c, An example of records obtained $90 \mathrm{~min}$ after cessation of the application. Calibration bars at the bottom apply to all of the records. B, Time course of changes in amplitude of the postsynaptic component of cortical field potentials evoked by test stimulation of LGN. The amplitude is expressed as percentage of the mean amplitude for $20 \mathrm{~min}$ before LFS. The horizontal thick bar indicates the LFS. At the top are shown examples of field potentials recorded at the time point indicated by corresponding letters in lower graph. Record 2 was obtained just before cessation of LFS. C, Pooled data from 14 rats. Vertical bars indicate 2 SEMs. In some cases, 2 SEMs are smaller than the symbol size. Values during LFS are not plotted for simplicity.

Single shocks applied to the LGN elicited a negative-going, prominent potential in the cortex (Fig. $1 \mathrm{Aa}$ ). The peak latency of this negative potential was $12-15 \mathrm{msec}$. This potential was blocked by kynurenic acid, an antagonist for ionotropic glutamate receptors, which was injected into the visual cortex through a cannula $(A b)$. After the cessation of injection, this potential recovered almost completely $(A c)$. Thus, this negative potential was thought to mainly reflect EPSPs generated in the cortex, although an involvement of action potentials cannot be excluded 
(Kimura et al., 1989; Kirkwood and Bear, 1994). Therefore, we measured the amplitude of the negative potential from its onset to peak in the present study. The effectiveness of kynurenic acid also indicated that the infusion system through cannula in the present study functioned, as expected.

\section{LTD was not induced by LFS in the visual cortex in vivo}

After stable baseline recordings for $20 \mathrm{~min}$, LFS at $1 \mathrm{~Hz}$ for $15 \mathrm{~min}$ was applied to the LGN, because LFS with such a parameter is known to reliably induce LTD in slice preparations of rat visual cortex (Kirkwood et al., 1993; Haruta et al., 1994). Each shock of LFS induced clearly distinguishable potentials in the cortex, although their amplitudes gradually decreased with the number of shocks (Fig. 1B2). Approximately 5-10 min after cessation of LFS, cortical field potentials recovered completely, indicating that LFS did not induce LTD in the visual cortex in vivo (Fig. 1 B3 and bottom graph). The mean amplitude of negative peak of field potentials measured $1 \mathrm{hr}$ after LFS was $102.1 \pm 3.7 \%$ (mean \pm SEM) of the control before LFS in 14 rats (Fig. $1 C$ ). This value was not significantly different from the control $(p>0.5)$. The ineffectiveness of LFS in the in vivo cortex might be attributable to stimulation of LGN, because LFS was applied to the white matter or layer IV in slice preparations. To test this possibility, we applied LFS to the underlying white matter and layer IV of the in vivo cortex. Stimulation of the underlying white matter and layer IV elicited field potentials with essentially the same waveform as that of LGN-induced potentials, although the peak latencies were much shorter (Fig. 2A,C, insets). As shown in Figure 2, LFS of either site did not induce LTD. The mean amplitudes of field potentials measured $1 \mathrm{hr}$ after LFS of white matter and layer IV were $98.4 \pm 2.8$ and $101.2 \pm 7.6 \%$ of the control, respectively (Fig. $2 B, D$ ). Both values were not significantly different from the control $(p>0.5)$

Previous studies in hippocampus reported that increasing the duration of LFS enhanced the synaptic depression (Montgomery and Madison, 2002) or saturated and stabilized the expressed LTD (Heynen et al., 2000). Thus, there is a possibility that LFS with longer duration might induce LTD in the in vivo cortex. To test this possibility, we increased the duration of LFS of LGN to 30 min and thus the number of pulses to 1800 . We found, however, that such a lengthy LFS did not induce LTD in 13 young rats, except for two cases in which LTD was induced. The mean amplitudes of field potentials measured $1 \mathrm{hr}$ after LFS was $96.6 \pm$ $7.3 \%$ of the control (Fig. 3A). This value was not significantly different from the control $(p>0.5)$.

Presence of spontaneous inputs from retinas is not a factor for the ineffectiveness of LFS in the in vivo cortex

As mentioned above, we could not induce LTD in the in vivo visual cortex by LFS of LGN, white matter, or layer IV, although LFS is reported to reliably induce LTD in slice preparations. One of the differences between the in vivo and slice preparations is the presence of spontaneous inputs from retinas in the in vivo preparations. Such spontaneous inputs might interfere with the induction of LTD by LFS. To test this possibility, we removed both eyes of 10 rats after having placed stimulating electrodes in LGN. In these enucleated rats also, we found that LTD was not induced by LFS (Fig. $3 B$ ). The mean amplitude of field potentials measured $1 \mathrm{hr}$ after LFS in the 10 enucleated rats was $103.3 \pm 7.3 \%$ of the control. This value was not significantly different from the control $(p>0.5)$. In these preparations, the severed central nerves might still generate spontaneous activity. To exclude such a possibility, we injected TTX into both eyes in another series of

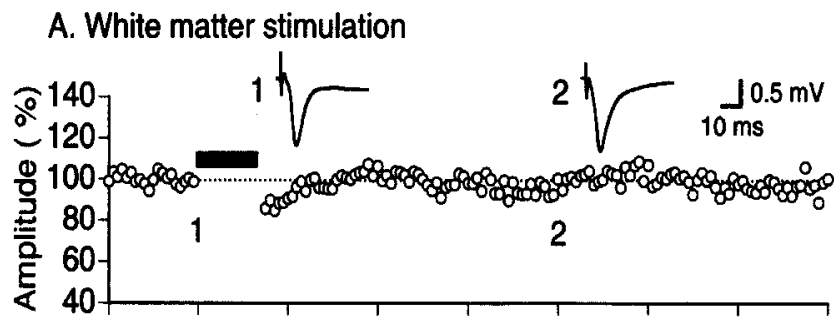

B. White matter stimulation

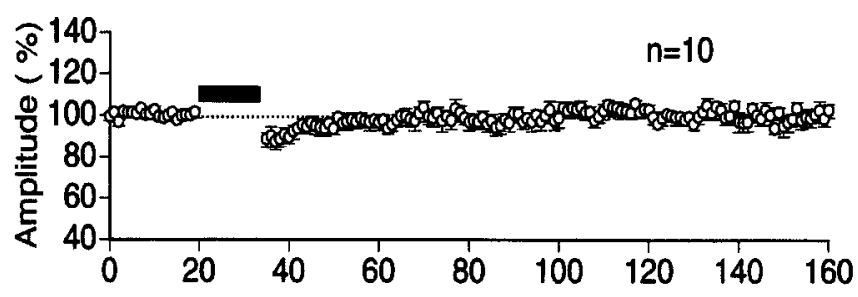

C. Layer IV stimulation

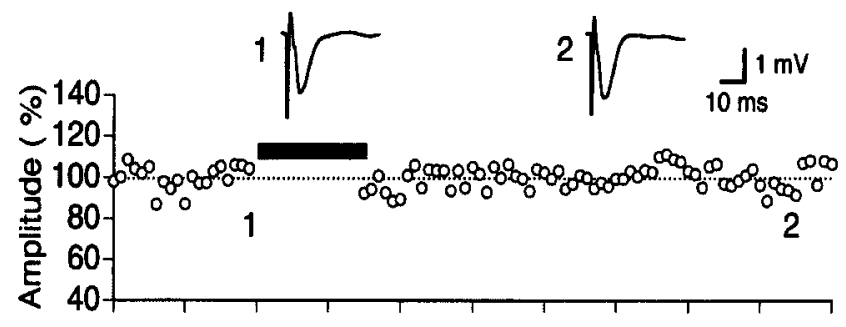

D. Layer IV stimulation

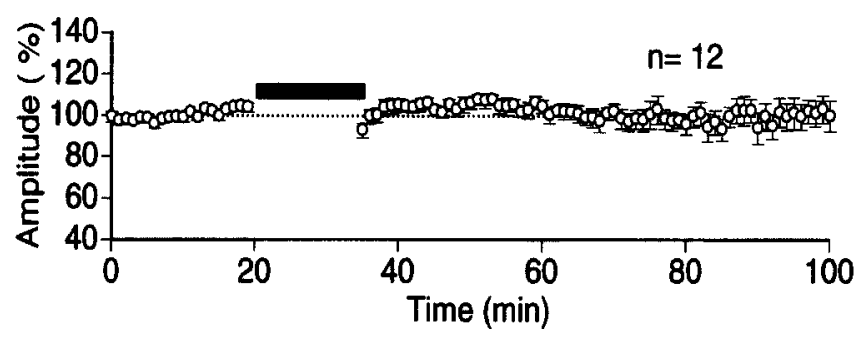

Figure 2. No induction of LTD in visual cortex in vivo by LFS of white matter or cortical layer IV. $A$, Time course of changes in the amplitude of cortical field potentials evoked by white matter stimulation. Conventions are the same as in Figure $1 B$. B, Pooled data from 10 rats. C, Time course of changes in the amplitude of field potentials evoked by test stimulation of cortical layer IV. Conventions are the same as in Figure 1B.D, Pooled data from 12 rats.

experiments. One hour after the injection, we observed a tonic dilation of pupil and a loss of direct pupillary reflex to light. Also, we confirmed that responses of LGN and visual cortex to photic stimulation given to both eyes completely disappeared. Then, cortical field potentials to electrical stimulation of LGN at 0.03 $\mathrm{Hz}$ were recorded for $20 \mathrm{~min}$, LFS was applied, and again field potentials to $0.03 \mathrm{~Hz}$ stimulation were recorded, as mentioned above. If the animals did not show a sign of recovery from the effect of TTX 24-30 hr after the injection, data from such animals were discarded from analysis to exclude possible effects of retinal lesions by the TTX injection. As shown in Figure 3C, the mean amplitude of field potentials measured $1 \mathrm{hr}$ after LFS in nine rats was $97.4 \pm 4.9 \%$ of the control. This value was not significantly different from the control $(p>0.5)$. These results indicate that the presence of spontaneous inputs from retinas is not a factor for the ineffectiveness of LFS for inducing LTD in the in vivo preparations. 


\section{A. LFS for $30 \mathrm{~min}$}

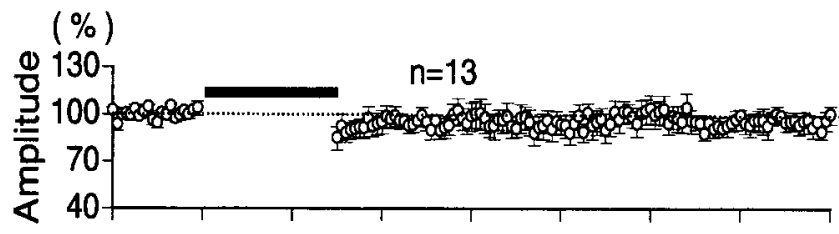

B. Enucleated

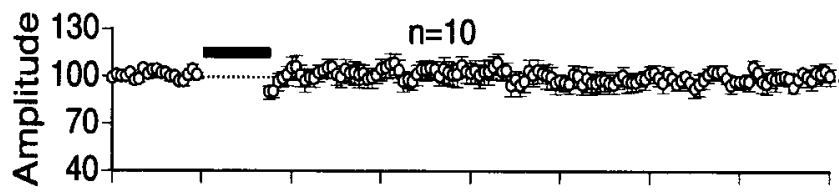

C. TTX injection

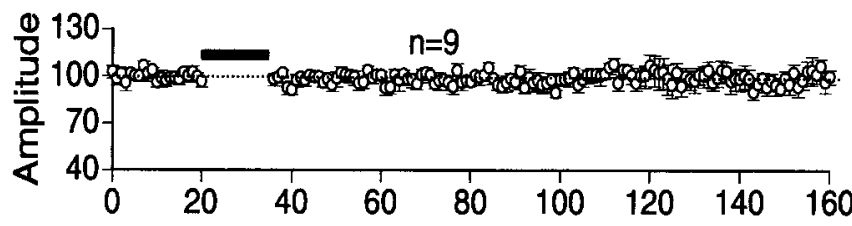

D. Slices at $31^{\circ} \mathrm{C}$

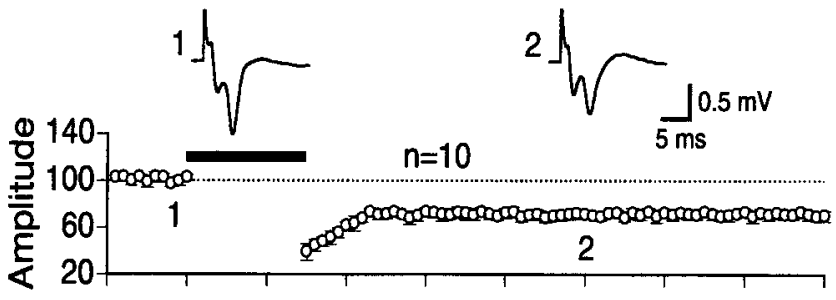

E. Slices at $37^{\circ} \mathrm{C}$

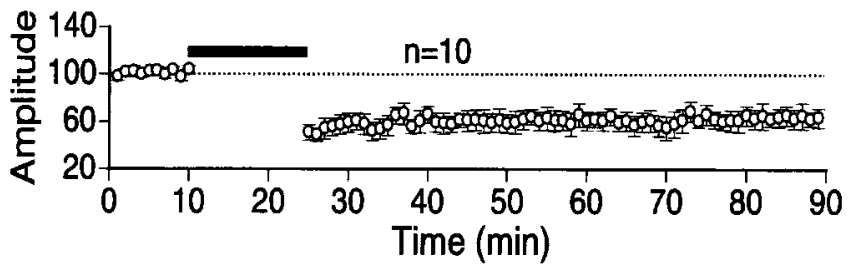

Figure 3. No induction of LTD by prolonged LFS $(A)$ or without retinal inputs $(B, C)$ in the in vivo condition and induction of LTD by the standard LFS in slice preparations at different temperatures $(D, E)$. $A$, Time course of changes in the mean amplitude of cortical field potentials evoked by LGN stimulation. The duration of LFS was lengthened to $30 \mathrm{~min}$. Pooled data from 13 rats. Other conventions are the same as in Figure $1 B$. $B$, Time course of changes in the mean amplitude of cortical field potentials evoked by LGN stimulation in 10 rats in which both eyes were removed 10 min before recordings. C, Time course of changes in the mean amplitude of cortical field potentials evoked by LGN stimulation in nine rats in which TTX was injected into both eyes $2 \mathrm{hr}$ before recordings. $D$, Time course of changes in the mean amplitude of field potentials recorded in visual cortical slices maintained at $31^{\circ} \mathrm{C}$. The amplitude is expressed as percentage of the baseline amplitude recorded for $10 \mathrm{~min}$ before LFS. Other conventions are the same as in Figure 1C. $E$, Time course of changes in the mean amplitude of field potentials recorded in visual cortical slices maintained at $37^{\circ} \mathrm{C}$. Other conventions are the same as in $D$.

Low temperature is not a factor for the effectiveness of LFS in slice preparations

Slice preparations in which LFS reliably induces LTD are usually maintained at $\sim 30^{\circ} \mathrm{C}$ or at room temperature. On the other hand, the in vivo preparations are naturally maintained at $\sim 37^{\circ} \mathrm{C}$. So, there is a possibility that the relatively high temperature of the in vivo preparations may be one of factors for the ineffectiveness of LFS for the induction of LTD. One might test this possibility by lowering the temperature of the brain in vivo, but this is practi- cally difficult. So, we instead tested whether LFS induces LTD in visual cortical slices at $37^{\circ} \mathrm{C}$. Initially we confirmed that LFS applied to layer IV elicited LTD of field potentials of layer II/III in slice preparations of 10 rats at $31^{\circ} \mathrm{C}$ (Fig. $3 D$ ). The mean amplitude of field potentials measured $1 \mathrm{hr}$ after LFS was $71.1 \pm 3.9 \%$ of the control. Then, we found that LFS was also effective for the induction of LTD at the temperature of $37^{\circ} \mathrm{C}$ (Fig. $3 E$ ). The mean amplitude of field potentials after LFS was $65.3 \pm 8.2 \%$ of the control. The magnitude of LTD recorded at 31 and $37^{\circ} \mathrm{C}$ was not significantly different $(p>0.5)$.

LTD is induced by LFS in the in vivo cortex infused with an inhibitor of Trk receptor tyrosine kinases

The question remained why LTD is not induced in the in vivo cortex, despite that it is reliably induced by the same protocol of LFS in slice preparations. Because previous studies using slices of rat visual cortex reported that exogenously applied BDNF prevents LFS from inducing LTD (Akaneya et al., 1996; Huber et al., 1998; Kinoshita et al., 1999), we hypothesized that activity of endogenous BNDF through activation of TrkB receptors in visual cortex in vivo may be a factor for preventing the induction of LTD. To test this hypothesis, we applied an inhibitor of Trk receptor tyrosine kinases, K252a, to visual cortex. A reliable LTD was induced when this inhibitor was applied to the cortex at the concentration of $20 \mu \mathrm{M}$ (Fig. 4A). The mean amplitude of field potentials $1 \mathrm{hr}$ after LFS was $78.6 \pm 3.8 \%$ of the control (Fig. 5, second column). The magnitude of LTD was dependent on the concentration of K252a. At the concentration of 10 and $40 \mu \mathrm{M}$, the mean amplitude of field potentials $1 \mathrm{hr}$ after LFS was $88.2 \pm$ 3.2 and $75.1 \pm 3.0 \%$ of the control, respectively (Fig. 5). The difference in the value between 10 and $20 \mu \mathrm{M}$ was significant, but that between 20 and $40 \mu \mathrm{M}$ was not. Thus, the action of K252a in the in vivo cortex seemed to be saturated at the concentration of $20 \mu \mathrm{M}$.

These results suggest that blockade or inactivation of TrkB signaling pathway is necessary for the induction of LTD in the cortex in vivo. Because $\mathrm{K} 252 \mathrm{a}$ is not a specific inhibitor of TrkB receptor activity, we then applied specific antibody that blocks function of TrkB receptors, anti-TrkB IgG1, into the cortex of nine rats. We first infused the cortex near the recording electrode with this antibody for $90 \mathrm{~min}$, and then test stimulation was applied to LGN until stable baseline recordings were obtained (usually for $20 \mathrm{~min}$ ). To see a possible effect of this antibody on basal synaptic transmission, we calculated the mean amplitude of field potentials $90 \mathrm{~min}$ after the infusion for these nine rats. It was $0.71 \pm 0.21 \mathrm{mV}$ (mean $\pm \mathrm{SD})$, which was not significantly $(p>$ $0.5)$ different from the control value $(0.73 \pm 0.18 \mathrm{mV})$, indicating that this antibody has no action on basal synaptic transmission in the visual cortex in vivo. In this condition, LFS induced strong LTD (Fig. $4 B$ ). The mean amplitude of field potentials measured $1 \mathrm{hr}$ after LFS was $74.9 \pm 4.4 \%$ of the control ( $p<0.01$ compared with the control). These results suggest that activity of TrkB signaling pathway contributes to the absence of LFS-induced LTD in the in vivo cortex.

\section{Endogenous BDNF but not NT4/5 is involved in the} prevention of LTD in the in vivo cortex

Because endogenous ligands for TrkB receptors are BNDF and NT4/5, a question arises which of these neurotrophins or both play a role in the prevention of LFS-induced LTD. To address this question, anti-BNDF antibody was infused into the visual cortex of 10 rats in the same way as anti-TrkB antibody. Initially we found that this antibody did not affect basal synaptic transmis- 


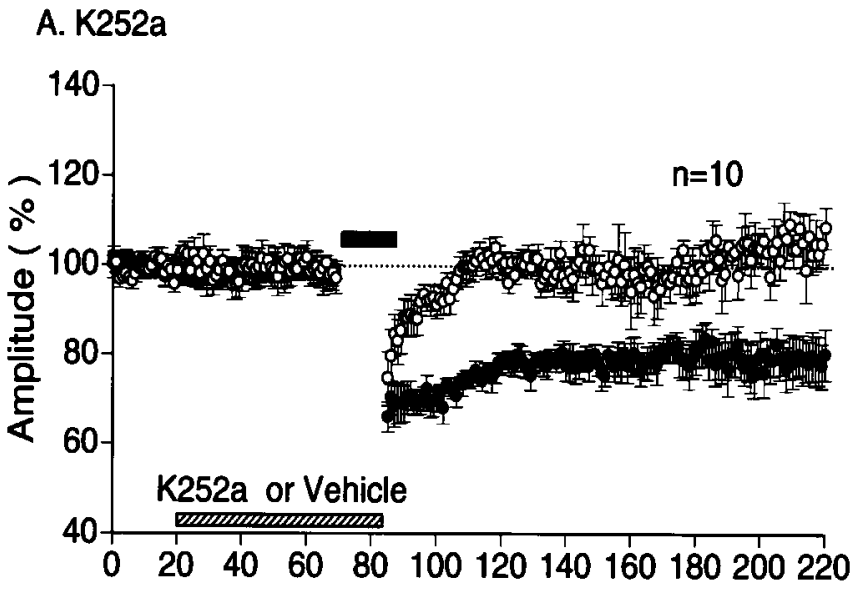

\section{B. Anti-Trk B IgG1}

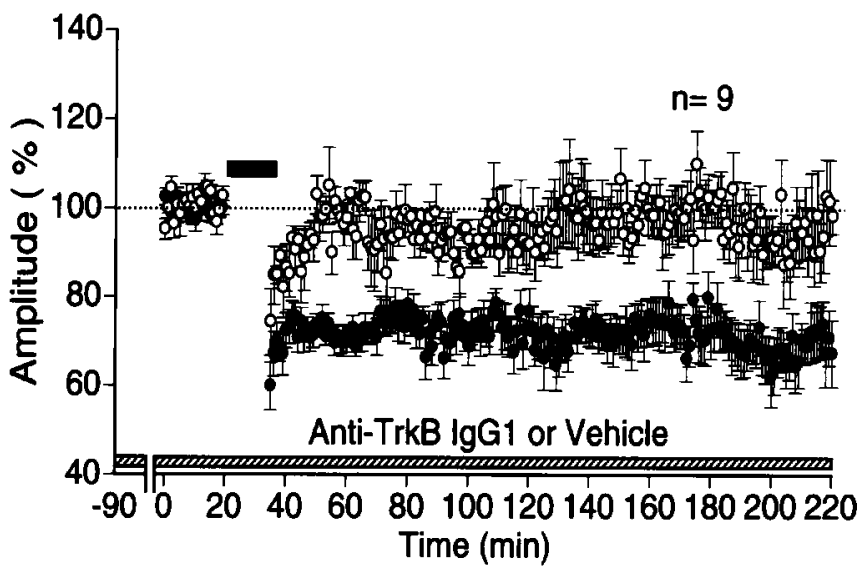

Figure 4. Induction of LTD by LFS in the in vivo cortex infused with K252a or anti-TrkB lgG1. $A$, Time course of changes in the mean amplitude of field potentials of visual cortex in vivo. The amplitude is expressed as percentage of the baseline amplitude recorded for $20 \mathrm{~min}$ before the application of K252a or vehicle solution. The hatched horizontal bar along the abscissa indicates the time when K252a or vehicle was applied. Data obtained with K252a are expressed by filled circles and those with vehicle by open circles. Other conventions are the same as in Figure 1C. $B$, Time course of changes in the mean amplitude of field potentials of visual cortex infused with anti-TrkB antibody or vehicle solution. Conventions are the same as in $A$.

sion. The mean amplitude of cortical field potentials to baseline stimulation $90 \mathrm{~min}$ after the application was $0.71 \pm 0.16 \mathrm{mV}$ (mean $\pm \mathrm{SD})$. This value was not significantly $(p>0.5)$ different from the control. In this condition, LFS induced significant LTD (Fig. 6A). The mean amplitude of field potentials measured $1 \mathrm{hr}$ after LFS was $77.4 \pm 3.6 \%$ of the control $(p<0.01$ compared with control). In contrast, LFS did not induce LTD when antiNT4/5 antibody was administered to the cortex (Fig. 6B). The mean amplitude of field potentials measured $1 \mathrm{hr}$ after LFS was $104.2 \pm 4.9 \%$ of the control ( $p>0.5$ ). To make sure that antiNT4/5 antibody infiltrated into the cortex sufficiently, we extended the infusion time before recordings from 90 to $150 \mathrm{~min}$ in five rats (Fig. $6 C$, note the difference in the left end of hatched horizontal bar along the abscissa between $B$ and $C$ ). In this condition also, LFS did not induce significant LTD. Then, we doubled the concentration of anti-NT4/5 antibody, but LFS was still ineffective (Fig. 6D).

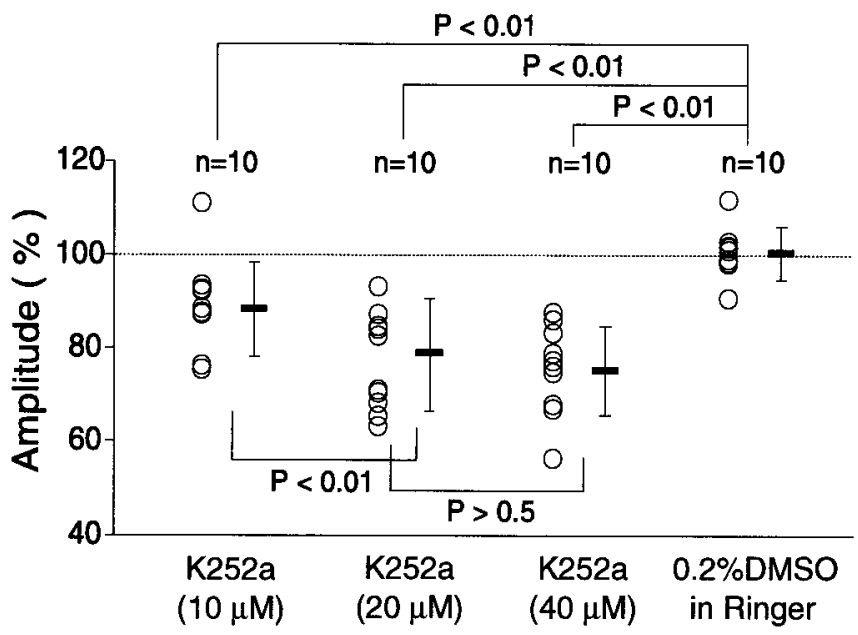

Figure 5. Summary of the results with K252a. Changes in the amplitude of field potentials 1 $\mathrm{hr}$ after LFS during the infusion of K252a or vehicle as percentage of baseline value before the infusion are plotted for each animal. Horizontal and vertical bars represent means and SDs for the same group of animals. The number of animals used for each test is shown at the top of each column. Statistical analysis was performed with one-way ANOVA, followed by Fisher's test.

Diffusion of antibodies in the cortex and blockade of Trk receptor activities

To confirm that the antibodies applied through the cannula diffused in the cortical region, including the site of field potential recordings, the cortex was stained with immunohistochemistry $\sim 30$ min after starting the injection of each type of antibody in six cases each. We found that all of the antibodies, anti-TrkB IgG1, anti-BDNF antibody, and anti-NT4/5 antibody, diffused and distributed widely in the visual cortex (Fig. 7A). There was no detectable difference in the extent of diffusion among these three kinds of antibodies. Then we attempted to see whether these antibodies effectively block function of their antigens in the in vivo condition. To test this, we performed Western blot analysis with anti-pY490-Trk antibody, which recognizes phosphorylated Trk receptors (Segal et al., 1996). With densitometry, we quantified the level of pY490-Trk immunoreactivity, which is an indicator of activity of full-length Trk receptors (Fig. $7 B$ ). As seen in Figure $7 B a$, the level of pY490-Trk was significantly reduced by K252a and each of the three antibodies, whereas the total protein level of full-length TrkB remained unchanged. This was confirmed by the group data (Fig. $7 \mathrm{Bb}$ ). The immunoreactivity of phosphorylated Trk receptors was $79.7 \pm 5.5,84.4 \pm 2.1,86.5 \pm$ 4.3 , and $87.4 \pm 5.6 \%$ of the control for K252a, anti-TrkB IgG1, anti-BDNF antibody, and anti-NT4/5 antibody, respectively. These values were significantly lower than the control, as indicated by asterisks in Figure $7 \mathrm{Bb}$. These results indicate that $\mathrm{K} 252 \mathrm{a}$ and each of the three antibodies exerted the blocking action in the cortex, as expected.

Decrease in TrkB immunoreactivity and Trk receptor phosphorylation in slice preparations

Finally, we addressed the question of why LTD was induced by LFS in slice preparations. Because the inactivation of BDNFTrkB system is shown to make LFS effective for the induction of LTD in the in vivo cortex, there is a possibility that the BDNFTrkB system is impaired or does not normally function in slice preparations. To test this possibility, we measured a possible time-dependent change in the level of phosphorylation of Trk receptors and the total protein level of full-length TrkB in slice preparations after the brains have been sliced. We found that 


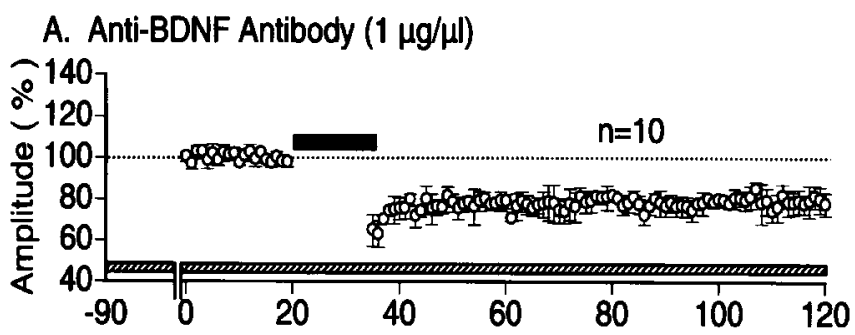

B. Anti-NT4/5 Antibody $(1 \mu \mathrm{g} / \mu \mathrm{l})$

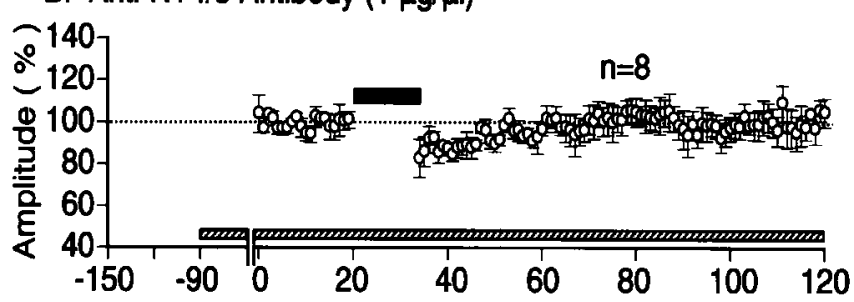

C. Anti-NT4/5 Antibody $(1 \mu \mathrm{g} / \mu \mathrm{l})$

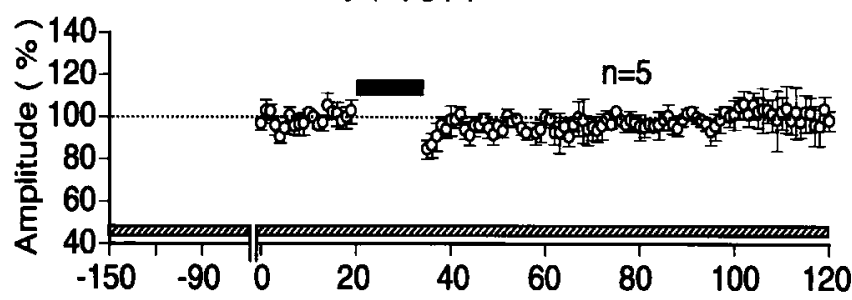

D. Anti-NT4/5 Antibody $(2 \mu \mathrm{g} / \mu \mathrm{l})$

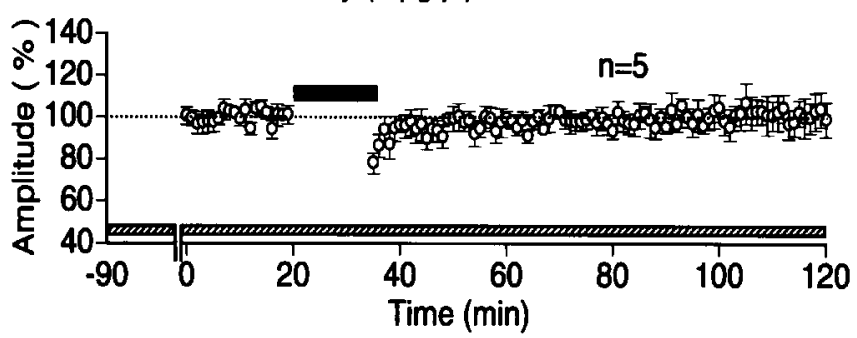

Figure 6. Induction of LTD by LFS when endogenous BDNF was blocked but no induction when endogenous NT4/5 was blocked. Time course of changes in the mean amplitude of cortical field potentials evoked by LGN stimulation during the application of anti-BDNF antibody $(A)$ and anti-NT4/5 antibody at the indicated concentration ( $B-D)$. Hatched horizontal bars along the abscissa indicate the time during which each antibody was applied to the cortex. Other conventions are the same as in Figure 1C. Note that the starting time of application in C was 150 min before the recording, whereas that in the others was $90 \mathrm{~min}$. Also note that the concentration of anti-NT4/5 antibody was increased to $2 \mu \mathrm{g} / \mu \mathrm{l}$ in $D$.

both protein levels decreased with time (Fig. 8). The mean level of both proteins $1 \mathrm{hr}$ after the brain has been sliced was significantly lower than the control. The level of both proteins further decreased with time. The densitometric values of immunoreactivity of anti-pY490-Trk at 1,2, and $4 \mathrm{hr}$ after slicing were $68.8 \pm 3.4$, $66.4 \pm 4.9$, and $49.5 \pm 5.6 \%$ of the control, and those of antiTrkB were $80.7 \pm 4.4,76.1 \pm 4.2$, and $66.2 \pm 3.1 \%$ of the control, respectively.

\section{Discussion}

In the present study, we found that LFS at $1 \mathrm{~Hz}$ for $15 \mathrm{~min}$, or even for $30 \mathrm{~min}$, is not an effective protocol of stimulation to induce LTD in the rat visual cortex in vivo, although the same parameter of LFS reliably induces LTD in slice preparations of the visual cortex of the rat (Fig. 3D) (also reported by Kirkwood et al., 1993; Haruta et al., 1994; Kirkwood and Bear, 1994; Sermasi et al., 1999; Perrett et al., 2001). Thus, it seems possible to state that LFSinduced homosynaptic LTD may be peculiar to slice preparations of the cortex. To draw such a conclusion, however, one should take into consideration differences between the in vivo and slice preparations.

Spontaneous inputs from the retina is not a factor for the ineffectiveness of LFS in vivo

In the in vivo preparations, neurons in the retina and LGN have spontaneous activities, even if the animals were very young or deprived from normal vision (Stryker and Harris, 1986; Maffei and Galli-Resta, 1990; Meister et al., 1991). Consequently, visual cortical neurons are expected to be bombarded by repetitive inputs originated from retinal spontaneous activity at various frequencies, as LGN cells were shown to relay them to the cortex (Mooney et al., 1996). On the other hand, cortical neurons in slice preparations have no inputs from the subcortical structures, including LGN. Thus, it seems possible that such spontaneous inputs might disturb the induction of LTD by LFS in the in vivo cortex. Previously, it was reported that the complete inactivation of retinas by intraocular injection of TTX reduced spontaneous activity of LGN neurons by $\sim 80 \%$ (Stryker and Harris, 1986; Rittenhouse et al., 1999). Thus, the enucleation or the intraocular injection of TTX is expected to reduce most inputs to the visual cortex, although some extraretinal inputs would remain. Even in such preparations, we found that LTD was not induced by LFS. Therefore, it seems reasonable to conclude that the ineffectiveness of LFS for the induction of LTD in the in vivo condition is not ascribable to spontaneous inputs from the retina.

Temperature is not a factor for the difference in effectiveness of LFS in slice and in vivo preparations

In rat hippocampal slices, it was reported that LFS at $1 \mathrm{~Hz}$ for 15 min became ineffective for the induction of LTD when the temperature of the perfusion medium increased from 32 to $39^{\circ} \mathrm{C}$ (Young et al., 2001). In the present study, we found that LFS of the same parameter was still effective for the induction of LTD in visual cortical slices when the temperature increased from 31 to $37^{\circ} \mathrm{C}$. The apparent discrepancy from the previous study might be ascribed to difference in the structure, hippocampus versus visual cortex, or in the temperature, $39^{\circ} \mathrm{C}$ versus $37^{\circ} \mathrm{C}$. Although we do not have direct evidence to distinguish these possibilities in the present study, we would like to point out that the average core temperature of the normal rat is between 37 and $38^{\circ} \mathrm{C}$ (Refinetti and Menaker, 1992). The higher temperature of slice preparations of the present study was within this range. At the body temperature, thus, LFS is effective for the induction of LTD in slice preparations but not so in the in vivo cortex.

\section{Endogenous BDNF as a factor for prevention of LTD in the} visual cortex in vivo

Previously, it was reported that an application of exogenous BDNF through the perfusion medium blocked the induction of LTD of excitatory synaptic transmission in slice and neuron culture preparations of rat visual cortex (Akaneya et al., 1996; Huber et al., 1998; Kinoshita et al., 1999; Kumura et al., 2000). In the present study, we observed that the functional blockade of the BDNF-TrkB system made LFS effective for the induction of LTD in the in vivo cortex. Thus, it seems reasonable to conclude that the action of endogenous BDNF through TrkB receptors prevents LFS from inducing LTD in the visual cortex in vivo. Then, a 
question arises why endogenous BDNF does not play such a role in slice preparations. The present results suggest that a reason for this may be the inactive state of BDNF-TrkB system, because we found that the protein level of TrkB in slice preparations of visual cortex reduced significantly $60 \mathrm{~min}$ after slicing, when field potential recordings were started. Such a reduction in the level of receptor protein was reported also in slice preparations of rat hippocampus: the protein level of the major subunit of AMPA type glutamate receptors, GluR1 and GluR3, started to decrease at $30 \mathrm{~min}$ after slicing and reached the very low value $30-330 \mathrm{~min}$ thereafter, although the protein level of BDNF did not significantly change (Taubenfeld et al., 2002). Thus, the insufficient activation of TrkB system is one of reasons why LFS could induce homosynaptic LTD in slice preparations of the visual cortex. In other words, the existence of active TrkB system in the in vivo cortex prevents LFS from inducing LTD.

There is another possible factor to be considered for the ineffectiveness of LFS in the in vivo condition. Previously, it was reported that BDNF is released by depolarization of cultured hippocampal neurons (Goodman et al., 1996) or highfrequency stimulation of primary sensory neurons in culture (Balkowiec and Katz, 2000). More recently, it has been reported that the release of BDNF from cultured hippocampal neurons was enhanced by high-frequency stimulation but not by lowfrequency stimulation (Gartner and Staiger, 2002). Thus, it seems likely that LFS of afferents in slice preparations could not release BDNF from presynaptic terminals to the extent to which it prevents the induction of LTD. On the other hand, inputs to visual cortical neurons during LFS in the in vivo preparations would contain high-frequency inputs in addition to regular $1 \mathrm{~Hz}$ inputs to the degree to which BDNF is released so as to prevent the induction of LTD. This seems consistent with the previous observation in visual cortical slices of guinea pigs that irregular stimulation including high-frequency with Poisson-distributed intervals did not induce LTD even when its duration was $15 \mathrm{~min}$ and the mean frequency was $1 \mathrm{~Hz}$ (Perrett et al., 2001). From this point of view, the previous observation that LTD induction was not changed by infusion of TrkB-IgG fusion proteins in visual cortical slices (Sermasi et al., 2000) could be accounted for as follows: in slice preparation, the release of BDNF would be very low so that the application of TrkB-IgG fusion proteins did not show any obvious action.

\section{No LTD-preventing action of NT4/5 in the visual cortex of young rats}

We observed that the application of anti-NT4/5 antibody did not make LFS effective for the induction of LTD, although it slightly reduced phosphorylation of Trk receptors. It was reported that exogenously applied NT4/5 blocked the effect of monocular deprivation in visual cortex during the critical period (Gillespie et al., 2000; Lodovichi et al., 2000) and rescued the shrinkage of
LGN neurons from effects of monocular deprivation (Riddle et al., 1995). In these studies, exogenously applied NT4/5 might activate TrkB receptors, which are activated by BDNF in the physiological condition. Using the sensitive immunoassay, it was reported that the concentration of endogenous NT4/5 protein is barely detectable in the rat brain (Zhang et al., 1999) and approximately $1 / 10$ of that of BDNF in the ferret visual cortex (Ichisaka et al., 2003). Also, it was reported that the protein level of NT4/5 did not change in response to input deprivation (Ichisaka et al., 2003). Therefore, endogenous NT4/5 in the visual cortex may not be released in an activity-dependent manner and thus not be involved in modification of synaptic transmission in the rat visual cortex.

\section{Possible pitfalls of LFS and slice preparations in the study of cortical LTD}

In the present study, we observed that LFS at $1 \mathrm{~Hz}$ for 15 min was not effective for inducing LTD in the in vivo condition. Thus, it seems possible to state that LFS-induced LTD may not operate in the in vivo visual cortex, although we cannot exclude an operation of any other type of LTD in the present study. This raises a concern about the usefulness of LFS as a protocol for the study of synaptic plasticity. In this context, it is to be pointed out that intervals between action potentials of cortical neurons in the physiological condition are usually irregular (Softky and Koch, 1993; Shadlen and Newsome, 1998; Stevens and Zador, 1998), and thus the present type of LFS with such a regular interval might be nonphysiological or even harmful to synaptic function in slice preparations, as discussed previously (Perrett et al., 2001). 

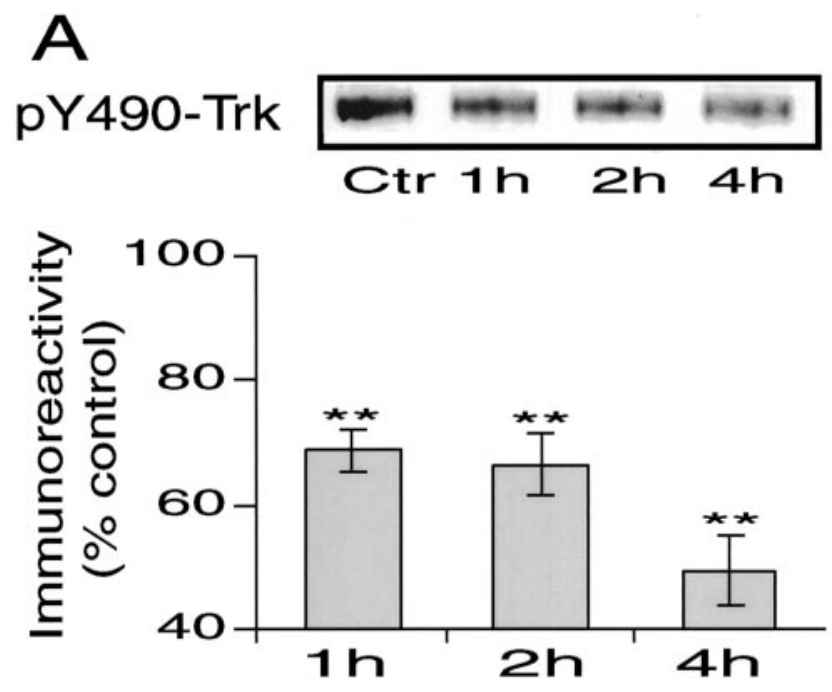

B
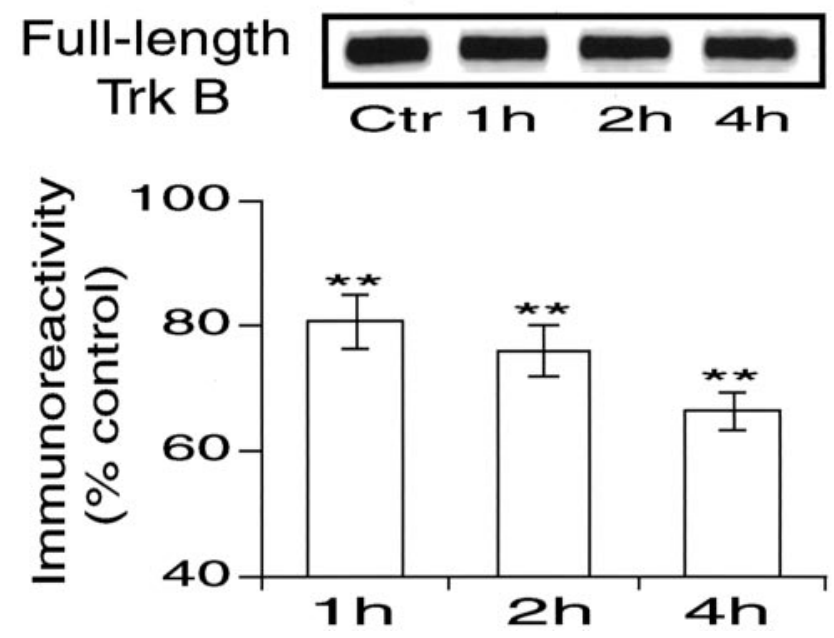

Figure 8. Reduction of p Y490-Trk $(A)$ and full-length TrkB $(B)$ immunoreactivity of cortical slices with time. $A$, Mean densitometric value of pY490-Trk immunoreactivity as percentage of the control value. Number of slices for each time, 14 . Vertical bars indicate 2 SEMs. ${ }^{* *} p<0.01$. At the top are shown representative immunoblots with anti-pY490-Trk antibody $(\sim 140 \mathrm{kDa}$ band). $B$, Mean densitometric value of anti-full-length TrkB immunoreactivity as percentage of the control value. Number of slices for each time, 10. At the top are shown representative immunoblots with anti-TrkB IgG1 ( $\sim 145 \mathrm{kDa}$ band, corresponding to full-length TrkB receptor protein). Other conventions are the same as in $A$.

In the present study, we also found that, in slice preparations, the levels of TrkB and phosphorylated Trks decrease with time. This raises another concern about usage of slice preparations as a tool for the study of cortical LTD. Thus, slice preparations of visual cortex should be used with caution in the study of LTD, although they may be useful to study other types of synaptic plasticity.

\section{References}

Akaneya Y, Tsumoto T, Hatanaka H (1996) Brain-derived neurotrophic factor blocks long-term depression in rat visual cortex. J Neurophysiol 76:4198-4201.

Akaneya Y, Tsumoto T, Kinoshita S, Hatanaka H (1997) Brain-derived neurotrophic factor enhances long-term potentiation in rat visual cortex. J Neurosci 17:6707-6716.

Balkowiec A, Katz DM (2000) Activity-dependent release of endogenous brain-derived neurotrophic factor from primary sensory neurons detected by ELISA in situ. J Neurosci 20:7417-7423.
Bear MF, Cooper LN, Ebner FF (1987) A physiological basis for a theory of synaptic modification. Science 237:42-48.

Desai NS, Cudmore RH, Nelson SB, Turrigiano GG (2002) Critical periods for experience-dependent synaptic scaling in visual cortex. Nat Neurosci 5:783-789.

Dudek SM, Friedlander MJ (1996) Developmental down-regulation of LTD in cortical layer IV and its independence of modulation by inhibition. Neuron 16:1097-1106.

Gartner A, Staiger V (2002) Neurotrophin secretion from hippocampal neurons evoked by long-term-potentiation-inducing electrical stimulation patterns. Proc Natl Acad Sci USA 99:6386-6391.

Gillespie DC, Crair MC, Stryker MP (2000) Neurotrophin-4/5 alters responses and blocks the effect of monocular deprivation in cat visual cortex during the critical period. J Neurosci 20:9174-9186.

Goodman LJ, Valverde J, Lim F, Geschwind MD, Federoff HJ, Geller AI, Hefti F (1996) Regulated release and polarized localization of brain-derived neurotrophic factor in hippocampal neurons. Mol Cell Neurosci 7:222-238.

Haruta H, Kamishita T, Hicks TP, Takahashi MP, Tsumoto T (1994) Induction of LTD but not LTP through metabotropic glutamate receptors in visual cortex. NeuroReport 5:1829-1832.

Heynen AJ, Quinlan EM, Bae DC, Bear MF (2000) Bidirectional, activitydependent regulation of glutamate receptors in the adult hippocampus in vivo. Neuron 28:527-536.

Huber KM, Sawtell NB, Bear MF (1998) Brain-derived neurotrophic factor alters the synaptic modification threshold in visual cortex. Neuropharmacology 37:571-579.

Ichisaka S, Katoh-Semba R, Hata Y, Ohshima M, Kameyama K, Tsumoto T (2003) Activity-dependent changes in the protein level of brain-derived neurotrophic factor but no change in other neurotrophins in the visual cortex of young and adult ferrets. Neuroscience 117:361-371.

Ikegaya Y, Ishizaka Y, Matsuki N (2002) BDNF attenuates hippocampal LTD via activation of phospholipase C: implications for a vertical shift in the frequency-response curve of synaptic plasticity. Eur J Neurosci 16:145-148.

Jiang B, Akaneya Y, Ohshima M, Ichisaka S, Hata Y, Tsumoto T (2001) Brain-derived neurotrophic factor induces long-lasting potentiation of synaptic transmission in visual cortex in vivo in young rats, but not in the adult. Eur J Neurosci 14:1219-1228.

Jiang B, Akaneya Y, Hata Y, Tsumoto T (2002) Endogenous BDNF prevents low frequency stimulation from inducing LTD in in vivo visual cortex of young rats. Soc Neurosci Abstr 28:647.10.

Katz LC, Shatz CJ (1996) Synaptic activity and the construction of cortical circuits. Science 274:1133-1138.

Kimura F, Nishigori A, Shirokawa T, Tsumoto T (1989) Long-term potentiation and $N$-methyl-D-aspartate receptors in the visual cortex of young rats. J Physiol (Lond) 414:125-144.

Kinoshita S, Yasuda H, Taniguchi N, Katoh-Semba R, Hatanaka H, Tsumoto $\mathrm{T}$ (1999) Brain-derived neurotrophic factor prevents low-frequency inputs from inducing long-term depression in the developing visual cortex. J Neurosci 19:2122-2130.

Kirkwood A, Bear MF (1994) Homosynaptic long-term depression in the visual cortex. J Neurosci 14:3404-3412.

Kirkwood A, Dudek SM, Gold JT, Aizenman CD, Bear MF (1993) Common forms of synaptic plasticity in the hippocampus and neocortex in vitro. Science 260:1518-1521.

Kumura E, Kimura F, Taniguchi N, Tsumoto T (2000) Brain-derived neurotrophic factor blocks long-term depression in solitary neurones cultured from the rat visual cortex. J Physiol (Lond) 524:195-204.

Linden DJ, Connor JA (1995) Long-term synaptic depression. Annu Rev Neurosci 18:319-357.

Lodovichi C, Berardi N, Pizzorusso T, Maffei L (2000) Effects of neurotrophins on cortical plasticity: same or different? J Neurosci 20:2155-2165.

Maffei K, Galli-Resta L (1990) Correlation in the discharges of neighboring rat retinal ganglion cells during prenatal life. Proc Natl Acad Sci USA 87:2861-2864.

Meister M, Wong RO, Baylor DA, Shatz CJ (1991) Synchronous bursts of action potentials in ganglion cells of the developing mammalian retina. Science 252:939-943.

Montgomery JM, Madison DV (2002) State-dependent heterogeneity in synaptic depression between pyramidal cell pairs. Neuron 33:765-777. 
Mooney R, Penn AA, Gallego R, Shatz CJ (1996) Thalamic relay of spontaneous retinal activity prior to vision. Neuron 17:979-990.

Perrett SP, Dudek SM, Eagleman D, Montague PR, Friedlander MJ (2001) LTD induction in adult visual cortex: role of stimulus timing and inhibition. J Neurosci 21:2308-2319.

Pollock GS, Vernon E, Forbes ME, Yan Q, Ma YT, Hsieh T, Robichon R, Frost DO, Johnson JE (2001) Effects of early visual experience and diurnal rhythms on BDNF mRNA and protein levels in the visual system, hippocampus, and cerebellum. J Neurosci 21:3923-3931.

Refinetti R, Menaker M (1992) The circadian rhythm of body temperature. Physiol Behav 51:613-637.

Riddle DR, Lo DC, Katz LC (1995) NT-4-mediated rescue of lateral geniculate neurons from effects of monocular deprivation. Nature 378:189-191.

Rittenhouse CD, Shouval HZ, Paradiso MA, Bear MF (1999) Monocular deprivation induces homosynaptic long-term depression in visual cortex. Nature 397:347-350.

Rossi FM, Bozzi Y, Pizzorusso T, Maffei L (1999) Monocular deprivation decreases brain-derived neurotrophic factor immunoreactivity in the rat visual cortex. Neuroscience 90:363-368

Segal RA, Bahattacharyya A, Rua LA, Alberta JA, Stephens RM, Kaplan DR, Stiles CD (1996) Differential utilization of trk autophosphorylation sites. J Biol Chem 271:20175-20181.

Sermasi E, Tropea D, Domenici L (1999) Long term depression is expressed during postnatal development in rat visual cortex: a role for visual experience. Dev Brain Res 113:61-65.

Sermasi E, Margotti E, Cattaneo A, Domenici L (2000) Trk B signalling controls LTP but not LTD expression in the developing rat visual cortex. Eur J Neurosci 12:1411-1419.

Shadlen MN, Newsome WT (1998) The variable discharge of cortical neu- rons: implications for connectivity, computation, and information coding. J Neurosci 18:3870-3896.

Singer W (1995) Development and plasticity of cortical processing architecture. Science 270:758-764.

Softky WR, Koch C (1993) The highly irregular firing of cortical cells is inconsistent with temporal integration of random EPSPs. J Neurosci 13:334-350.

Stevens CF, Zador AM (1998) Input synchrony and the irregular firing of cortical neurons. Nat Neurosci 1:210-217.

Stryker MP, Harris WA (1986) Binocular impulse blockade prevents the formation of ocular dominance columns in cat visual cortex. J Neurosci 6:2117-2133

Taubenfeld S, Stevens KA, Pollonini G, Ruggiero J, Alberini CM (2002) Profound molecular changes following hippocampal slice preparation: loss of AMPA receptor subunits and uncoupled mRNA/protein expression. J Neurochem 81:1348-1360.

Tropea D, Capsoni S, Tongiorgi E, Giannotta S, Cattaneo A, Domenici L (2001) Mismatch between BDNF mRNA and protein expression in the developing visual cortex: the role of visual experience. Eur J Neurosci 13:709-721.

Tsumoto T (1992) Long-term potentiation and long-term depression in the neocortex. Prog Neurobiol 39:209-228.

Tsumoto T, Suda K (1979) Cross-depression: An electrophysiological manifestation of binocular competition in the developing visual cortex. Brain Res 168:190-194.

Young C, Luo MZ, Shen YZ, Gean PW (2001) Dissociation between synaptic depression and block of long-term depression induced by raising the temperature in rat hippocampal slices. Synapse 40:27-34.

Zhang SH, Zhou XF, Deng YS, Rush RA (1999) Measurement of neurotrophin $4 / 5$ in rat tissues by a sensitive immunoassay. J Neurosci Methods 89:69-74. 